\title{
Ependymoma in pregnancy: one suspicion can save a life
}

\author{
Ankita Pandey*, Prasad Yeshwant Deshmukh, Madhuri Mehendale, Y. S. Nandanwar
}

Department of Obstetrics \& Gynaecology, LTMMC \& GH, Sion, Mumbai, Maharashtra, India

Received: 26 February 2015

Revised: 02 March 2015

Accepted: 18 April 2015

\section{*Correspondence:}

Dr. Ankita Pandey,

E-mail: sonamnrs86@gmail.com

Copyright: (C) the author(s), publisher and licensee Medip Academy. This is an open-access article distributed under the terms of the Creative Commons Attribution Non-Commercial License, which permits unrestricted non-commercial use, distribution, and reproduction in any medium, provided the original work is properly cited.

\section{ABSTRACT}

Ependymomas arise from ependymal cells that line the ventricles of the brain and the spinal canal. Ependymomas are relatively rare tumors accounting for 2-3\% of all primary brain tumors in adults. We present this case of ependymoma to highlight the fact that aggressive management might be keystone in saving mothers life and even after surgical intervention, it is possible that the tumour recurs and may prove fatal. Maternal outcome in primary brain tumours in pregnancy largely depend on histologic grade of primary tumour and gestational age at which they present.

Keywords: Neuroependymoma, Ventriculoperitoneal shunt, Decompression, Intracranial tension

\section{INTRODUCTION}

Neurologic conditions are one of the cause of maternal mortality and/or morbidity in pregnant women. The natural history of key neurologic conditions is available during pregnancy, providing a useful basis on which to counsel women and organize services. Less information is available regarding safety of treatment and investigations of neurological conditions in pregnancy and obstetric or neonatal outcomes for these women, as they are very rare almost 1 in every 50000 pregnancies. ${ }^{1}$ We present this case of ependymoma to highlight the fact that aggressive management might be keystone in saving mothers life and even after surgical intervention, it is possible that the tumour recurs and may prove fatal.

\section{CASE REPORT}

Mrs. ABC, 24 years female, resident of Navi Mumbai, primigravida with 9 month amenorrhoea, with period of gestation of $37.1(\mathrm{~B} / \mathrm{D})$ and $39(\mathrm{~B} / \mathrm{S})$. LMP 28/01/2014 and EDD 04/11/2014. ANC registered in other hospital and referred in view of past history of neurosurgery.
On review of previous papers, she had past history of excision of posterior fossa ependymoma grade II on 30/06/2014 under GA. Patient was alright for three months and on 15/10/2014 referrred to our hospital in view of blurring of vision, vomiting and headache. Urgent neurosurgery opinion was sought and plain CT scan was done, which revealed lesion in posterior fossa and cerebellum compressing on fourth ventricle. Urgent ventriculo-peritoneal shunt and LSCS was done in same sitting. Male child of $2360 \mathrm{~kg}$ was delivered. Postoperatively patient was started on intravenous antibiotics and inj. levatiracetam. Detailed ophthalmologic examination was done which revealed no papilloedema. Repeat CT brain was done suggestive of VP shunt in situ and decompressed lateral and fourth ventricle with posterior fossa oedema. On 26/10/2014, patient was transferred to neurosurgery side in view of persistent headache. MRI brain was done. Recurrent multicentric bilateral cerebellar, craniovertebral junction and fourth ventricular space were occupying lesion. Hence, decision was taken to operate on her. On 29/10/2014, first stage of exploration was done consisting of bilateral suboccipital craniotomy, excision of space occupying lesion at cranio vertebral junction, fourth ventricle and subcutaneous metastasis with lax 
duroplasty. Frozen section was suggestive of ependymoma. Postoperatively patient was kept on ventilatory support. She improved neurologically and was obeying commands. Post-operative CT scan was done on 30/10/2014 which was suggestive of persistent hydrocephalus and posterior fossa oedema. 24 hours post operatively, patient had increased drowsiness. On examination, VP Shunt chamber was collapsed and nonfunctional. Hence right frontal extraventricular drain was put achieving good CSF drainage. Patient was planned for second stage exploration consisting of extended sub occipital craniotomy and excision of tentorial and bilateral cerebellar convexity lesions with lax duroplasty was done. Postoperative scan showed reduced cerebellar oedema and good removal of posterior fossa lesions. Reduction in size of lateral ventricles with ventricular drain in position. In postoperative period, patient was having spontaneous eye opening, was responding to commands and was on ventilatory support. On 05/11/2014, patient developed status epilepticus and had cardiac arrest. Despite all resuscitative efforts could not be revived back.

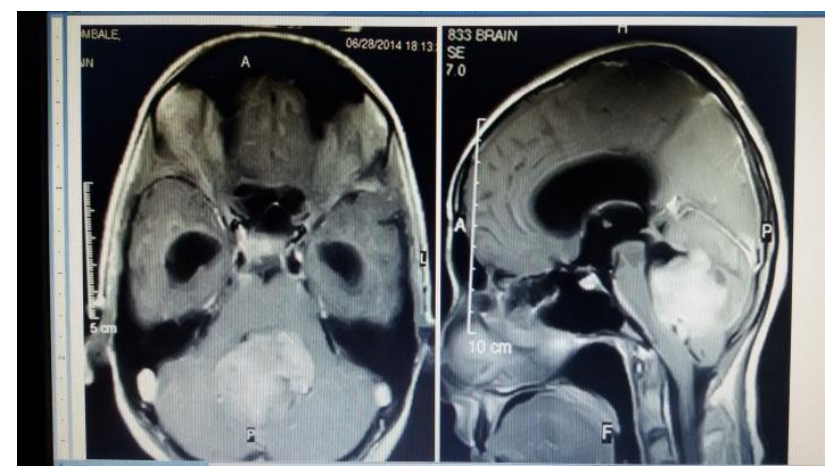

Figure 1: MRI brain showing posterior fossa tumour consequently dilated cerebral ventricles.

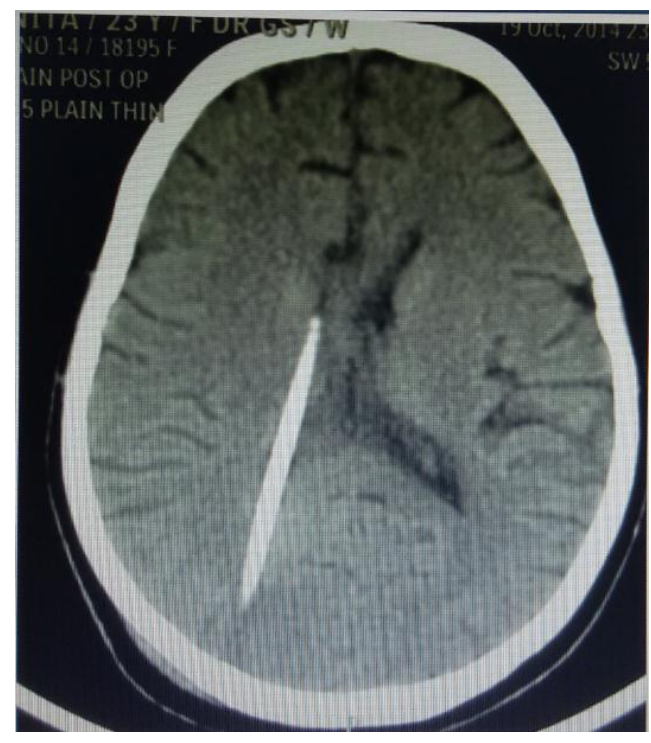

Figure 2: Cranial decompression with ventriculoperitoneal shunt in situ.

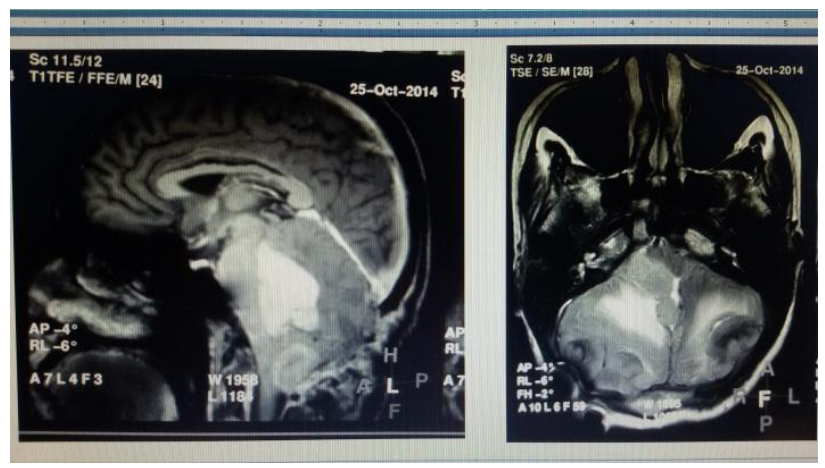

Figure 3: Post-surgical recurrence of posterior fossa tumour.

\section{DISCUSSION}

Ependymomas arise from ependymal cells that line the ventricles of the brain and the spinal canal. Ependymomas are relatively rare tumors accounting for $2-3 \%$ of all primary brain tumors in adults. They are not dependent on oestrogens or progesterones for their growth in contrast to meningioma, acoustic neuroma and prolactinoma, which show accelerated growth in hormonal milieu of pregnancy. ${ }^{2}$

- WHO Grade I: Subependymoma and myxopapillary ependymoma

- WHO Grade II: Ependymoma

- WHO Grade III: Anaplastic ependymoma

\section{Treatment}

The most important first step in the treatment of an ependymoma is surgery to remove as much tumor as possible. Studies clearly show that patients whose tumor can be "grossly" removed (removing all tumor that can be seen) have the best chance of long-term survival. Radiation therapy is usually recommended following surgery, even if all visible tumor was removed. Patients treated with radiation therapy following surgery generally have a better chance of long-term survival than patients treated with surgery alone. Chemotherapy has not shown efficacy in the treatment of ependymomas. The extent of tumor removal continues to be the strongest factor influencing recurrence and survival. Age at diagnosis, amount of residual tumor is remaining after surgery, whether the tumor has spread, and the therapy given can all influence outcome. In an adult age group, cases diagnosed with Anaplastic Ependymoma with tumour location in brain had worst outcome. ${ }^{3}$ Further, cases diagnosed to have supratentorial location had worst outcome and in such cases, local irradiation had better effect on quality of life than doing incomplete excision. ${ }^{4}$

Re-operation when possible followed by additional therapy, can be helpful. Re-irradiation (possibly with radiosurgery) is done to the areas of tumor recurrence. 


\section{CONCLUSIONS}

The best opportunity to treat tumours of neural origin is for the person who treats it in first attempt. As subsequent attempts are likely to be associated with recurrence and more complications for such tumours like Ependymoma, for which there is very high recurrence rate. Maternal outcome in primary brain tumours in pregnancy largely depend on histologic grade of primary tumour and gestational age at which they present. Timing and mode of therapy as well as maternal and foetal benefit also play a crucial role in management of such patients.

Funding: No funding sources Conflict of interest: None declared

Ethical approval: Not required

\section{REFERENCES}

1. American College of Radiology. Guidelines for imaging pregnant women with ionizing radiation. In: ARC, eds. ARC Guideline. Reston, VA: ARC Council; 2008

2. Roelvink NC, Kamphorst W, Van Alphen HA. Pregnancy related primary brain and spinal tumours. Arch Neurol. 1987;44(2):209-15.

3. Vilano JL, Parker CK, Dolecek TA. Descriptive epidemiology of brain tumours. $\mathrm{Br} \mathrm{J}$ Cancer. 2013;108(11):2367-71.

4. Dützmann S, Schatlo B, Lobrinus A, Murek M, Wostrack M, Weiss C, et al. A retrospective analysis of quality of life in adult patients with cranial ependymoma. J Neurooncol. 2013;114(3):319-27.

DOI: 10.18203/2320-1770.ijrcog20150105

Cite this article as: Pandey A, Deshmukh PY, Mehendale M, Nandanwar YS. Ependymoma in pregnancy: one suspicion can save a life. Int J Reprod Contracept Obstet Gynecol 2015;4:843-5. 